\title{
Analysis of More Tropical Cyclone Genesis over the Western North Pacific in 2016
}

\author{
Jian Li \\ Key Laboratory of Meteorological Disaster of Ministry of Education, Collaborative Innovation Center on Forecast and \\ Evaluation of Meteorological Disasters, Nanjing University of Information Science \& Technology, Nanjing, China \\ Email: jianlinuist@qq.com
}

How to cite this paper: Li, J. (2019). Analysis of More Tropical Cyclone Genesis over the Western North Pacific in 2016. Journal of Geoscience and Environment Protection, 7, 181-197. https://doi.org/10.4236/gep.2019.712013

Received: August 12, 2019

Accepted: December 27, 2019

Published: December 30, 2019

Copyright () 2019 by author(s) and Scientific Research Publishing Inc. This work is licensed under the Creative Commons Attribution International License (CC BY 4.0).

http://creativecommons.org/licenses/by/4.0/

(c) (i) Open Access

\begin{abstract}
Tropical cyclone (TC) is the most catastrophic weather system characterized by strong winds and heavy rains, and is therefore the main research object of tropical meteorology. Based on National Oceanic and Atmospheric Administration (NOAA) Sea Surface Temperature (SST), Outgoing Long wave Radiation (OLR) and National Centers for Environmental Prediction (NCEP) monthly reanalysis data and Regional Specialized Meteorological Center (RSMC) Tokyo best track data and China Meteorological Administration (CMA) tropical cyclone during 1979-2016, we analyze the feathers of tropical cyclones and causes of more tropical cyclones (TCs) over the western north Pacific(including the South China Sea) (WNP) in 2016. The results show that compared the number of tropical cyclone genesis was higher, the originated time was later and concentrated in autumn, the region of more cyclones formed in north and east, and the number of landing TCs was higher. Negative sea surface temperature anomaly in the equatorial eastern Pacific and a westward deviation of the ascending branch of Walker circulation can strengthen the intensity of convection activity based on an existing lead-lag correlation during the period of TC activity (from August to September).The West Pacific subtropical high (WPSH) was exceptionally stronger than in other years and its west ridge point appreciably stretched westward and northward from August to September in 2016, which is favorable to TC genesis. At the same time, $\omega$ positive anomaly located in northward which was favorable for more TC genesis in WNP. In addition, the anomalous distribution of environmental factors such as low vorticity, OLR and vertical wind shear may also be the cause of the formation of tropical cyclones in the West North Pacific in 2016.
\end{abstract}

\section{Keywords}

Western North Pacific, Sea Surface Temperature, Western Pacific Subtropical 
High, Environmental Factors

\section{Introduction}

Tropical cyclone (TC) is the most catastrophic weather system characterized by strong winds and heavy rains, and is therefore the main research object of tropical meteorology. Landing in tropical cyclones affects the country's economic and social development. The Western North Pacific (WNP) is the most active area of TC. Studies have shown that there are 1571 tropical cyclones in WNP, with an average of 35 per-year. $70 \%$ of these TCs will develop into typhoons. On average, about 25 TCs reach the intensity above tropical storms, accounting for $36 \%$ of the total number of tropical storms in the world, more than twice that of other sea areas. At the same time, there are obvious seasonal changes that the most frequent occurrences are in August and September for TCs and the least is in February. The typhoon season (July-October), which TCs, TS or TY account for more than $70 \%$ of the year $(\mathrm{Hu}, 2011)$. There are many factors affecting the formation of tropical cyclone in the western Pacific, such as the wind vertical shear (Bai et al., 2010), the North Atlantic Oscillation anomaly (Zhou \& Cui, 2014), the subtropical high (Lai, 2011). Studies have shown that there is a close relationship between the tropical Pacific SST anomaly and the frequency anomaly of TC formation in WNP (Chan, 1985; Dong, 1988; Lander, 1993). The abnormal changes in the ascending and descending branches of the Walker circulation affected by El Niño will cause frequency changes in the tc generation in the western North Pacific (Chan, 1985; Wu \& Lan, 1992). The abnormal rise of the Walker circulation in the El Niño development year is located in the central equatorial Pacific, and the anomalous descending in WNP, inhibiting convection in the west, which is not conducive to the formation of TC in WNP (Chan, 1985); Wu \& Lan (1992) shows that the downdraft over the Indonesian archipelago inhibited the northwest Pacific monsoon trough and associated westerly winds, reducing tropical storms in the Pacific Northwest.

Li (1985) pointed out that El Niño's development year is not conducive to evaporative condensation due to the abnormally low sea temperature in WNP. On the other hand, the large atmospheric static stability and the abnormal ascending of the Walker circulation are not conducive to the development of small scale of cumulus convection, and TC is not easy to generate in WNP. He et al. (1999) argued that El Niño's development of annual sea-air interactions caused anomalous changes in the tropical subtropical atmospheric circulation, which caused the subtropical high to be southward, cumulus convective activity weakened and the equatorial convergence zone was inactive, which is not conducive to the formation of TCs, so El Niño has less typhoon activity during the development year. On the contrary, La Niña's large-scale environmental field is conducive to the formation and development of tropical cyclones. The above studies show that ENSO can affect the frequency of tropical cyclone formation in the 
western North Pacific.

Previous studies have discussed the characteristics of strong El Niño TC activity (Maue, 2011; Liu \& Chan, 2013), and it is understood that the cause of TC frequency in August-September 2016 is significantly higher than the climate value has not been studied. In order to verify whether TC activity occurs in a specific season, we compared TC frequency in different seasons and found that there was no TC generation in the first half of 2016 (January-June), and 18 TCs in the active season (July-September). The generation is more than normal. Higher TC generation frequencies may be associated with large-scale circulation in response to tropical ocean surface temperature (SST) anomalies due to the effects of SST (Wu \& Lan, 1992; Emanuel, 2005). In the winter of 2015, the SST in the tropical Middle East and the Pacific Ocean was abnormally high, and it was the strongest El Niño year and the intensity was the strongest since 1951. The El Niño event ended in May 2016 (Ren et al., 2016). The activity of the TC in WNP from August to September 2016 has many significant features. We analyzed the causes of TC generation in order to provide some reference information for short-term climate prediction of TC.

\section{Data}

The recent track data set of 2016 TC data are provided by Japan RSMC Tokyo Typhoon Center. Since the data does not provide data for landing typhoon, the typhoon data is recorded in the 74 circulation index provided by the National Climate Center for supplement. We take the July-September period as the active season of the typhoon and focus on TC activities from August to September. The climate average is based on the average of 1979-2016. The characteristic index of the West Pacific Subtropical High (hereinafter referred to as the subtropical high) from 1952 to 2016 are adopted from the National Climate Center. NOAA monthly sea surface temperature from $1979-2016$, resolution of $2.0^{\circ} \times 2.0^{\circ}$; OLR from $1979-2016$, resolution $2.5^{\circ} \times 2.5^{\circ}$. The monthly NCEP/NCAR reanalysis.

\section{Results and Analysis}

\subsection{Characteristics of TC in WNP and South China Sea in 2016}

Figure 1 shows the interannual trend distribution of the number of TCs from 1979 to 2016. The statistical results show that the number of TCs generated in WNP and the South China Sea in 2016 is 26, significantly more than the climate (1979-2016) that 25.4. Among them, there are 9 Super-TYs, 3 STYs, 2 TYs, and the rest are tropical storms and tropical depression. The TC activity time is mainly concentrated in July-November, and the main time period is from August to September, with 14 in total, accounting for $53.8 \%$ of the total. Among them, the number of typhoons that landed was seven, accounting for $26.9 \%$ of the total number of TCs in the whole year, which was higher than the average annual average (25.9\%). It can also be seen from Figure 1 that since 2008, the number of TC generations has increased, which indicates that the number of TC generation frequencies in 2016 is too high. 


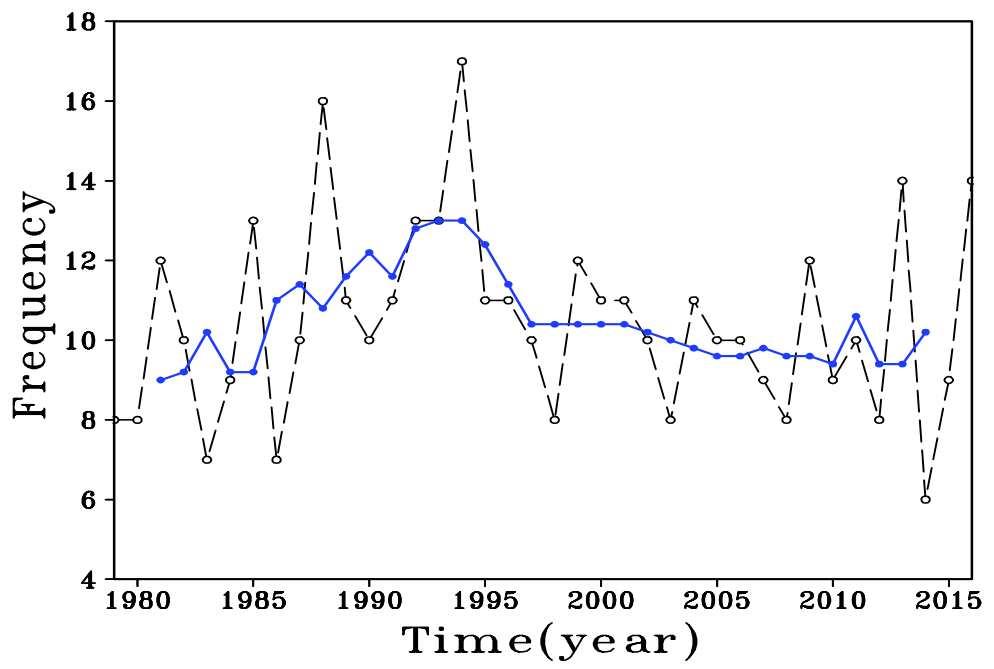

Figure 1. Annual TC count during 1979-2016 (The solid line represents 5 points slide average; the dashed line stands for climatological mean of TC count).

The number of TCs generated in the strong El Niño decayed year is 26, where no TC is generated from January to June, and the number of TC formation is significantly more in August-September. It is apparent that the frequency of TC formation in WNP has obvious interannual characteristics. Compared with the monthly distribution of TC climate values in 2016, it is found that the 2016 TC generation period is mainly concentrated in July-October, totaling 21 , accounting for $80.7 \%$ of the total TC number. No TC generation in January-June, the average annual deviation Less, August was significantly more than the climatic average of 1.63 and 1.92, respectively, and was the month with the largest number of generations in the year. During the typhoon active season (July-September), the number of TC generations in August and September was one of the more years since the years of 1979-2015, with 17 in 1994 and August-September 2013. And 14 TCs (figure omitted).

Strong El Niño Attenuation Year TC generation source latitude and longitude east, north, mostly steering track (Chen \& Ding, 1979; He et al., 1999). This paper counts the southeastern Pacific Ocean $\left(0^{\circ}-15^{\circ} \mathrm{N}, 120^{\circ} \mathrm{E}-180^{\circ}\right)$ in 2016 , the northeastern Pacific Northwest $\left(15^{\circ}-30^{\circ} \mathrm{N}, 120^{\circ} \mathrm{E}-180^{\circ}\right)$, and the South China Sea $\left(0^{\circ}-23^{\circ} \mathrm{N}, 105^{\circ}-120^{\circ} \mathrm{E}\right)$ (Table 1$)$. The number of TCs generated during the active season of the typhoon active season. Here, the latitude and longitude of the central latitude when the TC reaches the intensity of the tropical storm (TS) is used as a criterion for judging the position of the TC.

It is apparent from Table 1 that there are four TCs in the southeastern Pacific Ocean, which are $30 \%$ lower than the climatological average, accounting for $15.3 \%$ of the TC number, and less generated. The average number of TCs in the northeast is 11 and 42.3 in the same period. \%, which is greater than the average number of years, the typhoon active season was mostly generated in August and September; at the same time, there were 3 in the South China Sea, accounting for 
Table 1. Number of tropical cyclone monthly frequency over the WNP in 2016.

\begin{tabular}{cccccccccccc}
\hline Moth & $1-3$ & 4 & 5 & 6 & 7 & 8 & 9 & 10 & 11 & 12 & Total \\
\hline 2016 & 0 & 0 & 0 & 0 & 4 & 7 & 7 & 4 & 3 & 1 & 26 \\
Climate & 0.31 & 0.63 & 1.13 & 1.79 & 3.65 & 5.37 & 5.08 & 3.61 & 2.13 & 1.15 & 25.4 \\
\hline
\end{tabular}

$11.5 \%$ of the total TC number in the same period, which was higher than the climate average of 2. The 2016 TC distribution in the Northwest Pacific is consistent with the general rule of the strong El Niño next year. The number of TCs in the northeastern part of the Pacific Northwest and the South China Sea is more than that in the southwestern Pacific.

Figure 2 shows the distribution of typhoon paths from August to September in 2016. It can be clearly seen from the figure that the typhoon paths in August-September 2016 are mostly turning lines, and the northeast direction is deflected, indicating that TC is generated in the eastern Pacific Ocean. More than one.

Figure 3 shows the monthly distribution of strong typhoons and super typhoons in the Western Pacific from 1979 to 2016. It can be seen from the figure that there were 26 TC generations, and the number of TCs with strong typhoon strength was 12 in 2016, above average 10.5. The number of TCs with strong typhoon intensity above September and October was 5 and 3 respectively, significantly more than 2.1 and 1.9 of the climatic values, especially in the Pacific Northwest where there were 3 tropical cyclones, and All three TCs have developed into super typhoon levels. One of the most striking features of the tropical cyclone generated in 2016 was the strong typhoon activity in the autumn, especially the 1614 super typhoon "Morante" was one of the strongest typhoons in history. When it landed in Xiamen, Fujian at 03:00 on September 15. The maximum wind speed near the center is $48.8 \mathrm{~m} / \mathrm{s}$, which is the strongest typhoon landing in Fujian since the founding of the People's Republic of China.

\subsection{Influence of SST, Low-Level Airflow and OLR}

The high sea surface temperature is the basis for the general disturbance to develop into structure with a warm core. The SST of the TC generation source needs to maintain above 26.5 for the whole year, because the warm sea surface contains a large amount of energy to enable the lower layer to have a high temperature and high humidity atmosphere. The higher the temperature of the sea surface, the higher the temperature of the lower layer and the more moisture increases by the turbulent flow between the sea and the air, so that the TC disturbance obtains a large amount of warm and humid air in the lower layer, and releases a large amount of latent heat of condensation through the convection of the cumulus cloud. The warm core structure has been developed. Chen \& Huang (2009) pointed out that when the SST of the TC generation source is negative, the initial disturbance supply energy is reduced, which is not conducive to the formation and maintenance of the warm core structure and the development 


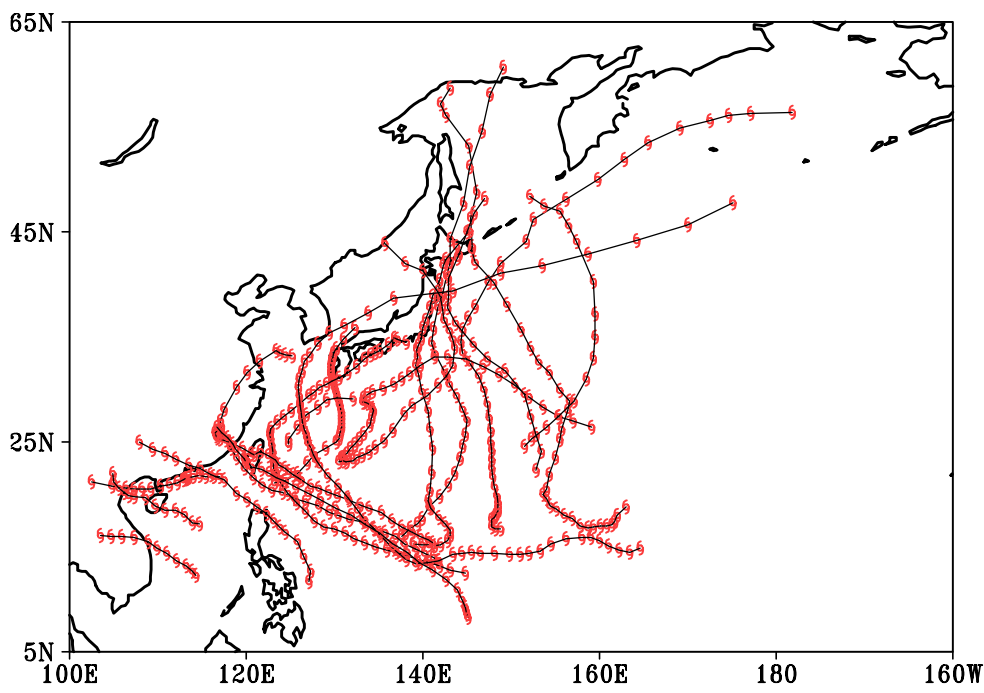

Figure 2. TC tracks over the WNP from August to September in 2016.

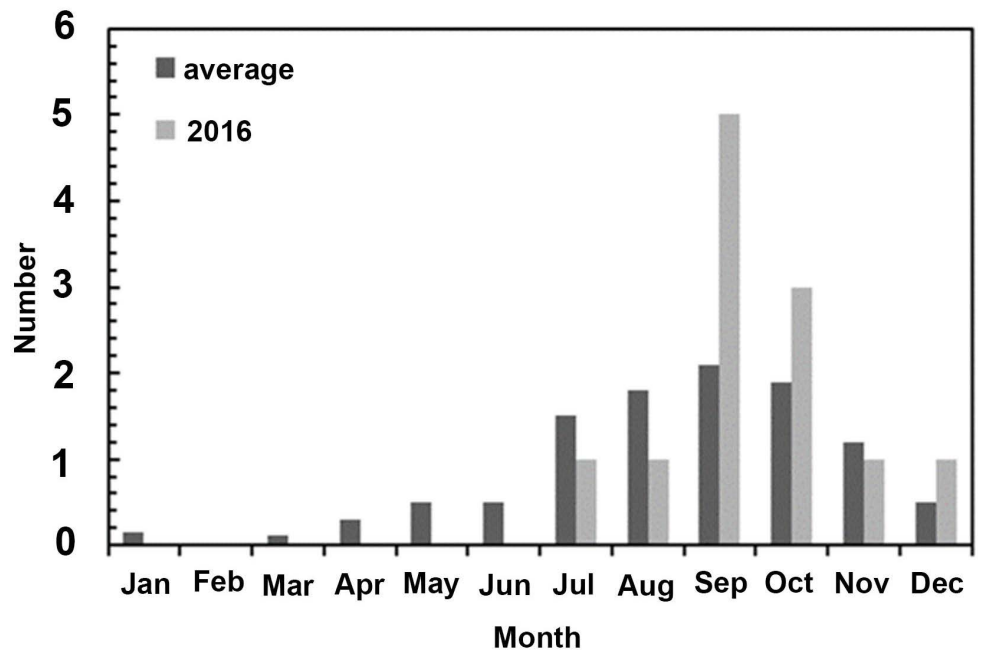

Figure 3. Monthly number of STY and Super-TY over the WNP in 2016.

of tropical cyclones is difficult to develop. When the SST is negative, the atmospheric stability will increase, and the cumulative energy of convection will decrease, so the number of tropical cyclones generated is small. When the tropical SST is abnormal, the atmospheric stability will be weakened. By co-coupling between the sea and the air, the convective activity in this sea area can be strengthened and contribute to the formation and development of TC. Figure 4 is the SST and low-level flow field anomaly from August to September 2016. It can be seen from Figure 4 that most of the sea surface temperature in WNP in August-September 2016 is positive and the sea temperature is high. However, there is a large-scale westerly anomaly in west of $140^{\circ} \mathrm{E}$, which makes TC unfavorable for generation and development.

The most important feature of the formation of typhoon is the warm-cored structure on the upper level. The OLR is the outward long-wave radiation of the geoelectric system detected by the satellite. It can indicate the temperature of the 


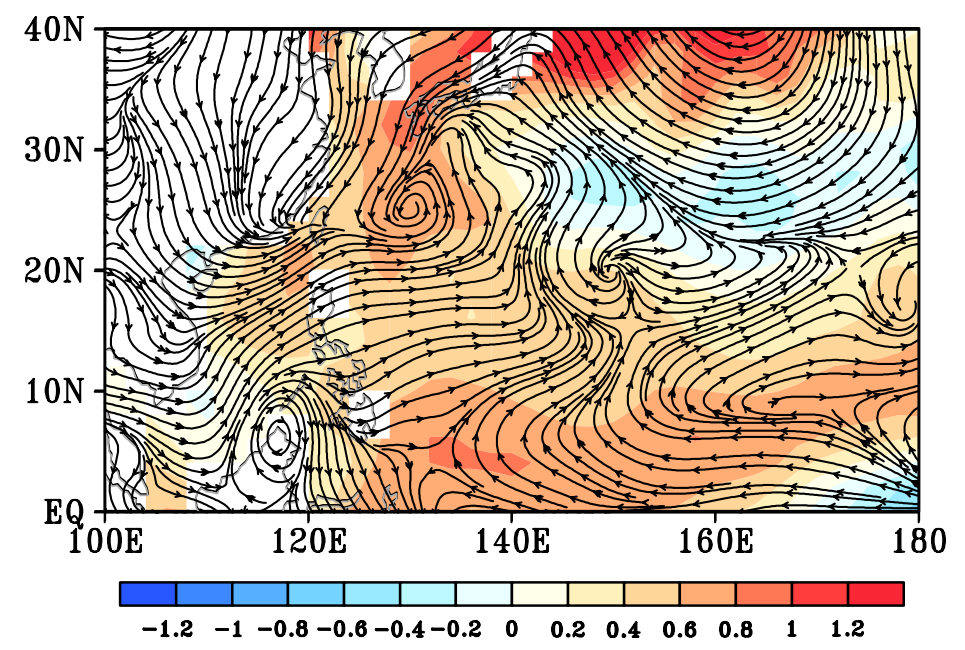

Figure 4. SST (unit: ${ }^{\circ} \mathrm{C}$ ) and stream (unit: $\mathrm{m} / \mathrm{s}$ ) anomaly in $1000 \mathrm{hPa}$.

cloud top, and the low-value area indicates that the convective high value area indicates convection attenuation. It can better reflect the convective development intensity and large-scale vertical motion in the tropical atmospheric circulation, and can represent the changes of the tropical convergence zone and the subtropical high body. The sea area surrounded by $250 \mathrm{~W} / \mathrm{m}^{2}$ is the area of the western Pacific subtropical high (Yao et al., 2006).

Figure 5 shows the climate average and anomaly OLR distribution from $\mathrm{Au}$ gust to September 2016. It can be seen that the average position of the sub-high in August-September is located north of $25^{\circ} \mathrm{N}$ in the western Pacific, and the northerly elevation is favorable for the formation of TC.

From the corresponding western Pacific OLR anomaly map (Figure 4), the OLR anomaly is negative between $15^{\circ}-25^{\circ} \mathrm{N}$, the convective activity is abnormally strong, and the convective anomaly center is located in the northern waters of the western Pacific. In the east of $140^{\circ} \mathrm{E}$, the OLR anomalies north of $5^{\circ} \mathrm{N}$ and $30^{\circ} \mathrm{N}$ are positive, corresponding to the above-mentioned sub-high body, the maximum OLR maximum positive anomaly reaches $15 \mathrm{~W} / \mathrm{m}^{2}$, indicating the subtropical high intensity on the northeastern ocean surface is stronger. the OLR anomaly of the ocean surface is basically the largest negative center of $-20 \mathrm{~W} / \mathrm{m}^{2}$ in $144^{\circ} \mathrm{E}$, indicating that the convective activity of the atmosphere in the northeastern part of the South China Sea and the western Pacific Ocean is strong. The atmospheric stratification is relatively unstable, also revealing the eastern Pacific Ocean eastward $170^{\circ}$ E. The negative anomaly of the SST (Figure 4). The negative anomaly of the SST will cause positive anomalies in the western Pacific Walker circulation, which is conducive to the convective activity that is beneficial to the TC generation and development (Huang et al., 2009). Therefore, the strength of convective activities is related to the number of typhoons generated in August-September 2016, and the source of the source is north.

The anomaly of the SST caused the vertical movement anomaly of the TC generation source. It can be seen from the anomalous vertical velocity distribution in the Northwest Pacific (Figure 6). The $120^{\circ} \mathrm{E}$ is controlled by the 

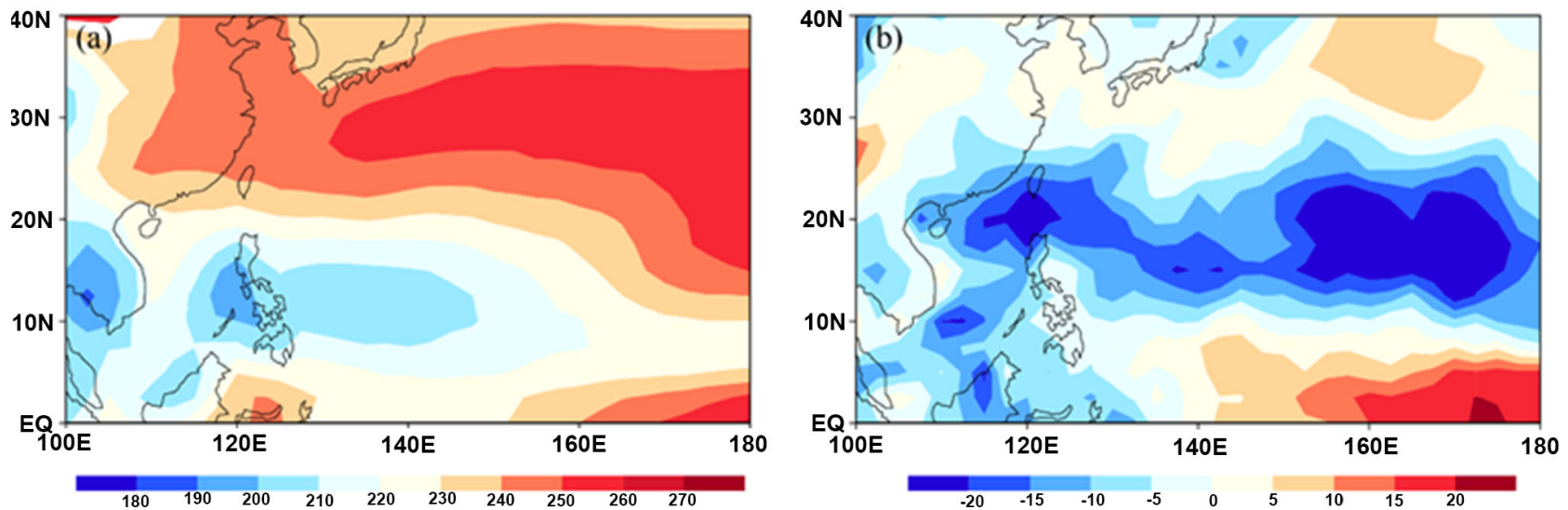

Figure 5. (a) Climate average OLR (unit: $\mathrm{W} / \mathrm{m}^{2}$ ), (b) OLR (unit: $\mathrm{W} / \mathrm{m}^{2}$ ) anomaly.

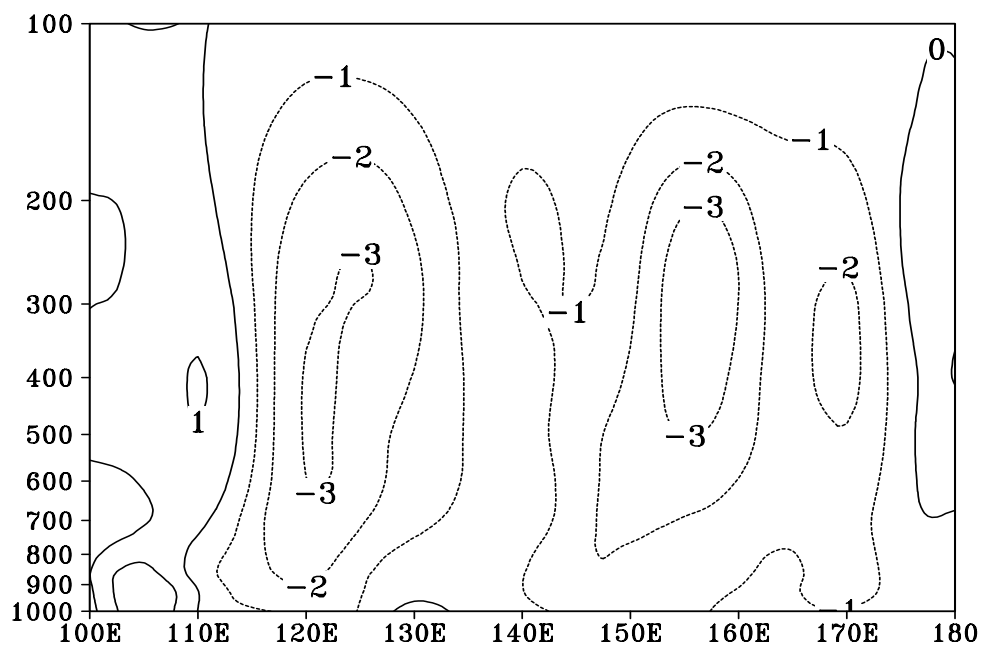

Figure 6. Pressure-longitude section of $\omega$ anomaly (unit: $10^{-2} \mathrm{~Pa} / \mathrm{s}$ ) over the WNP $\left(0-40^{\circ} \mathrm{E}\right)$ from August to September in 2016.

abnormal updraft in the large area of the East, West and Pacific Oceans. The maximum achievable level is $-0.05 \mathrm{~Pa} / \mathrm{s}$, the updraft is strong, and the initial disturbance of the lower layer is easy to form, which is conducive to the development of convective activity. Therefore, the number of TC generation in the eastern Pacific Ocean is higher in August-September. Tropical cyclones are a type of convective activity system that appears on a tropical scale on a tropical scale. The convective activity continues to occur because of the warm and humid air in the lower layers, the unstable stratification and the low-altitude convergence. Therefore, the tropical cyclone is formed in the convergence region of the low-altitude positive vorticity on the warm ocean surface.

Figure 7 shows the $850 \mathrm{hPa}$ airflow field anomaly and relative vorticity anomaly from August to September 2016. It is obvious that the eastward anomaly is large in the east of $130^{\circ} \mathrm{E}$, which is basically consistent with the flow field distribution in Figure 4 . Between $-25^{\circ} \mathrm{N}$ is a large area of positive vorticity anomaly, and the maximum positive vorticity anomaly center value is $2 \times 10^{-5} \mathrm{~s}^{-1}$, indicating that the lower layer convergence motion is stronger in the northwestern 


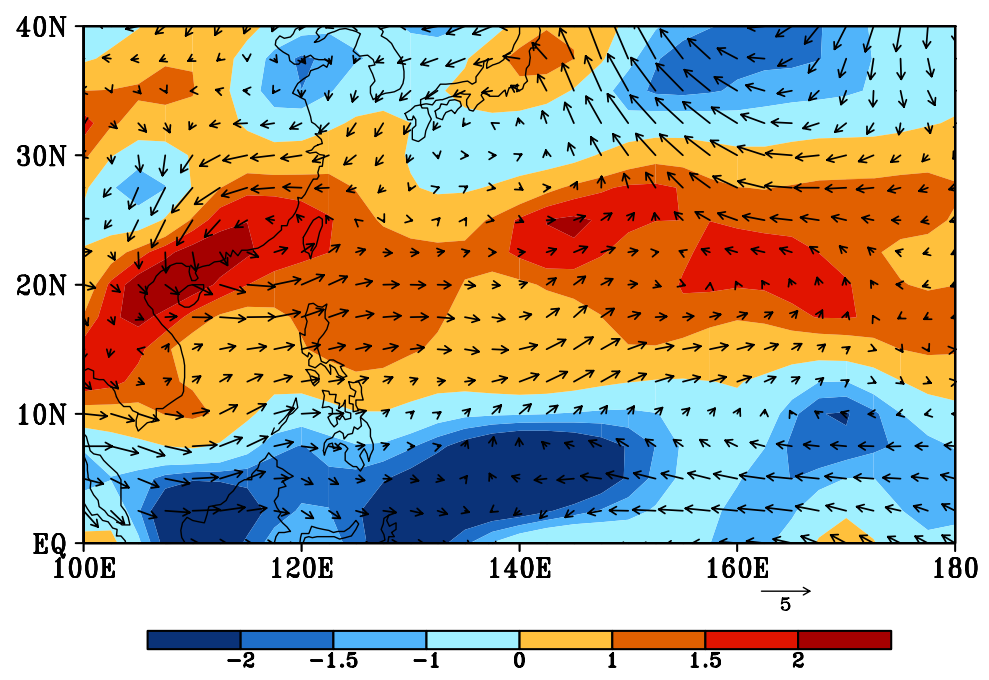

Figure 7. Wind field anomaly (streamline, unit: $\mathrm{m} / \mathrm{s}$ ) and relative vorticity anomaly (unit: $10^{5} \mathrm{~s}^{-1}$ ) at $850 \mathrm{hPa}$ from August to September in 2016.

part of the western Pacific and the South China Sea. The area where the ascending airflow is located is basically the same, further indicating that the TC activity is easy to generate and develop in this area, while the southeastern part of the western Pacific is controlled by large-area negative vorticity anomalies, in which there is an abnormal downdraft (Figure 6). It is not conducive to the development of initial disturbance, and the number of TC generation is less. Therefore, the number of TCs generated in WNP in 2016 was more than normal.

\subsection{Impact of Subtropical High}

The subtropical high system is an important component that restricts atmospheric circulation changes, especially during the typhoon active season. The evolution of the subtropical high (including location, intensity, etc.) has an important impact on the formation and path of tropical cyclones in the western Pacific. The position of the subtropical high ridge line is southerly and the intensity is stronger, which is not conducive to the formation of TC. The position of the subtropical high ridge line is northerly and the intensity is weaker, which is conducive to the formation of TC (Chen \& Ding, 1979; Shen \& Jiang, 2010). This paper explores the influence of the strong northwestern Pacific subtropical high on the frequency of TC in strong El Niño. Table 2 compares the characteristics of the sub-high index of the strong El Niño in August-September, and finds the sub-high ridge of the strong El Niño next year.

Both the line and the northern boundary are more northerly than normal, which is conducive to the formation of TC $(\mathrm{Li}, 1988)$. On the other hand, the intensity and area ofthe sub-annual average of the strong El Niño are higher than the multi-year average, which is not conducive to TC. Generation. Are there any contradictions between the anomalies in area and intensity of the subtropical high and the effects of ridge and north anomalies on TC generation? We saw that the number of TCs in August and September of 2016 was 1.8 more than 
Table 2. Characteristic index of the subtropical high from August to September in weak El Niño years.

\begin{tabular}{cccccc}
\hline & $\begin{array}{c}\text { Subtropical } \\
\text { high ridge } /{ }^{\circ} \mathrm{N}\end{array}$ & $\begin{array}{c}\text { Subtropical } \\
\text { high north } /{ }^{\circ} \mathrm{N}\end{array}$ & $\begin{array}{c}\text { Westward } \\
\text { ridge } /{ }^{\circ} \mathrm{E}\end{array}$ & $\begin{array}{c}\text { Area index } \\
/ 10^{5} \mathrm{~km}^{2}\end{array}$ & $\begin{array}{c}\text { Intensity index } \\
/ 10^{6} \mathrm{~km}^{2} \cdot \text { dagm }^{2}\end{array}$ \\
\hline 1958 & 31 & 31 & 120 & 23 & 40 \\
1966 & 30 & 34 & 124 & 23 & 41 \\
1973 & 22 & 34 & 107 & 24 & 53 \\
1983 & 21 & 29 & 105 & 28 & 55 \\
1988 & 22 & 24 & 115 & 26 & 55 \\
1998 & 25 & 34 & 92 & 37 & 73 \\
Average in strong & 24.5 & 31.0 & 110.5 & 32.2 & 52.8 \\
El Niño years & 25.4 & 30.8 & 119.5 & 21.2 & 38.6 \\
Multi-year average & 29 & 33 & 109 & 21.5 & 53 \\
\hline 2016 & 29 & & &
\end{tabular}

normal, but the number of TCs above TS was 0.8 less than the mean, and the number of TCs above TS was less than that of previous years (Table 1). It indicates that the intensity and area ofthe sub-high is too large, which is not conducive to enhancing the activity intensity of TC, which does not conflict with the number of TC generation. The tropical cyclone is a vortex guided by the ambient airflow, and the airflow around the subtropical high has a guiding effect on the TC movement (Vitart et al., 1999; Zhu et al., 2007). The subtropical high westward ridge point is slightly westward, causing the TC track to turn later (Figure 2), the number of TCs landing in China is too large, so the strong El Niño TC track in the next year has a turn to the northeast.

Compared with the perennial, the subtropical high position in August-September 2016 is northerly, the area is larger and intensity are stronger, and the west extension ridge point is westward. This conclusion is consistent with the result of the OLR used to represent the subtropical high area in Figure 5. Conducive to the tropical cyclone of the western Pacific landing in China, the TC track is northerly, which also causes the formed time of TC to be concentrated late. Figure 8 shows that the south of $15^{\circ} \mathrm{N}$ is controlled by the tropospheric low-level anomalous downdraft, and the convective activity is developed. Being suppressed is not conducive to the development of TC generation. The $20^{\circ}-30^{\circ} \mathrm{N}$ to the troposphere is an abnormal updraft. Compared with the normal period, the maximum vertical velocity anomaly center is between $850 \mathrm{hPa}$ and $300 \mathrm{hPa}$, and the vertical velocity is $-6 \times 10^{-2} \mathrm{~Pa} / \mathrm{s}$. It is very conducive to the development of convective disturbances.

Comparing Figure 5, it can be seen that the positions of the low-level cyclone and anti-cyclonic anomalies correspond to the rising sinking airflow, further indicating that such vertical velocity distribution makes the convective activity in the northeastern Pacific and the South China Sea stronger. It is conducive to the development of low-level disturbances, the number of TC generation is more 


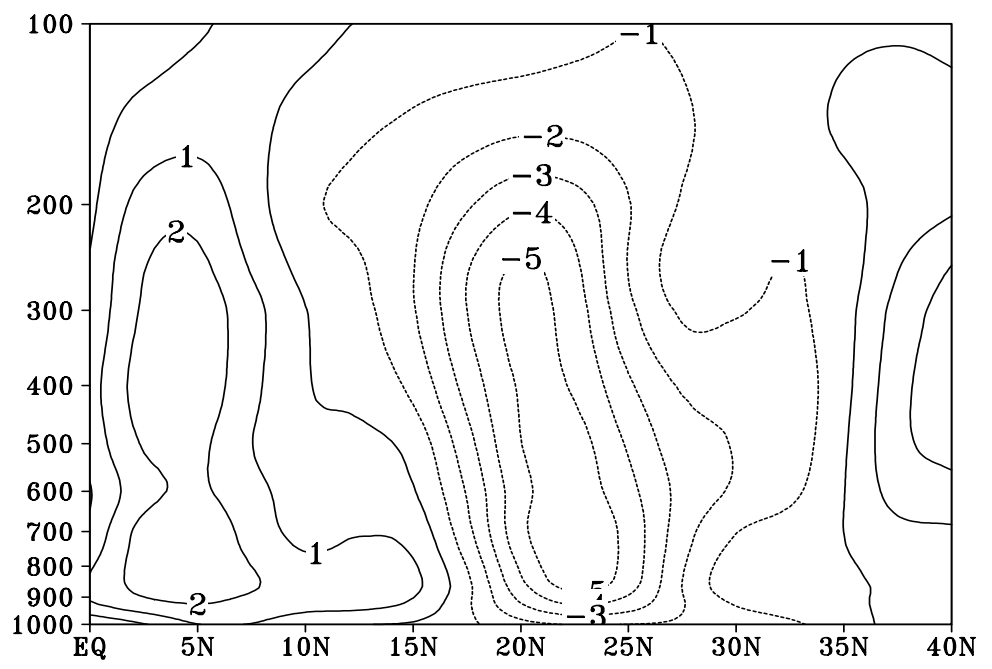

Figure 8. Pressure-latitude section of $\omega$ anomaly (unit: $10^{-2} \mathrm{~Pa} / \mathrm{s}$ ) over the West Pacific $\left(120^{\circ} \mathrm{E}-180^{\circ}\right)$ from August to September in 2016.

than that, while the low-level disturbances in the southeast are suppressed, and the number of generations is less. Therefore, it can be shown that the evolution of the subtropical high is closely related to the TC generation.

\subsection{Influence of Vertical Wind Shear}

The tropospheric vertical wind shear has a great influence on the development of tropical cyclones. The weak vertical wind shear indicates that the relative motion of the upper and lower air in the troposphere is small, and the latent heat released by the condensation is always concentrated in a limited range, and the warm core structure can be quickly formed and maintained, and the initial disturbance of the air pressure is continuously reduced, and the TC is developed (Ding \&Wright, 1984; Latif et al., 2007; Bai et al., 2010). The tropospheric vertical shear is small, that is, the basic airflow is less baroclinic, that is, the tropical cyclone develops in an environment of near positive pressure.

Figure 9 shows the tropospheric vertical wind shear anomaly from August to September 2016. It can be seen from the figure that in the active season of typhoon in 2016 (July-September), the vertical wind cuts into a negative anomaly in the large area south of $20^{\circ} \mathrm{N}$ in September and September, and the maximum negative anomaly center reaches $-4 \mathrm{~m} / \mathrm{s}$. The zonal vertical wind shear is smaller than normal, including the northeastern Pacific Northwest $\left(15^{\circ}-30^{\circ} \mathrm{N}, 120^{\circ} \mathrm{E}\right.$ $\left.180^{\circ}\right)$ and the South China Sea $\left(0^{\circ}-24^{\circ} \mathrm{N}, 105^{\circ} \mathrm{E}-120^{\circ}\right)$ region.

The vertical shear of the wind is basically negative anomaly, and the vertical shear of the wind is small and easy to form and develop the warm heart structure, which is conducive to the formation of tropical storms (Sun, 2010); in contrast to the southeastern Pacific Ocean $\left.\left(0^{\circ}\right)-15^{\circ} \mathrm{N}, 120^{\circ} \mathrm{E}-180^{\circ} \mathrm{E}\right)$ The wind vertical shear is mostly positive anomaly, and the maximum wind vertical shear positive distance is $8 \mathrm{~m} / \mathrm{s}$, indicating that the vertical shear is stronger than normal, and the vertical wind shear is higher. Large, limiting the development of 


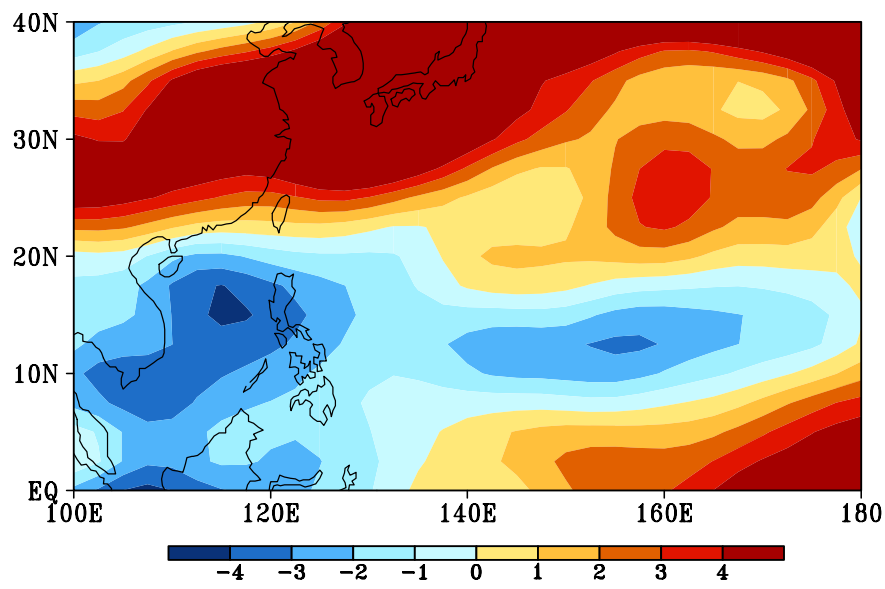

Figure 9. Vertical wind shear (U200 hPa-U850 hPa) anomaly (unit: $\mathrm{m} / \mathrm{s}$ ) from August to September in 2016.

convective activities. Therefore, the zonal vertical wind shear of the troposphere makes the number of TC generation in the northeastern Pacific Ocean and the South China Sea in 2016 more than in the southeast, while the TC generation in the southeast is less.

\subsection{Impact of Monsoon Trough}

The monsoon trough is formed by the south equatorial southwestern wind (southwest monsoon) and the southeast trade wind south of the subtropical high in the northern hemisphere from the northern Indian Ocean to the South China Sea. It belongs to the tropical convergence zone. Because the monsoon trough belongs to the equatorial convergence trough that the water vapor in the trough is abundant and the lower layer is the cyclonic vorticity of the environmental field, which is conducive to the initial disturbance of the lower layer and the high-level to anti-cyclonic flow. The field is very beneficial to the formation and development of tropical cyclones. According to statistics, $73 \%$ of the TC generation source is in the monsoon trough. Generally, the stronger the monsoon trough and the northerly position are favorable for the formation of TC (Wang et al., 2006; Gao et al., 2008).

Shen \& Jiang (2010) pointed out that the typhoon has a relatively concentrated area of typhoon generation $\left(5^{\circ}-25^{\circ} \mathrm{N}, 110^{\circ}-165^{\circ} \mathrm{E}\right)$. The eastern of the monsoon trough can reach east of $155^{\circ} \mathrm{E}$, and the eastern of the juvenile only reaches $145^{\circ} \mathrm{E}$. Due to the broad ocean surface near $150^{\circ} \mathrm{E}$, the warm sea temperature enhances the convective activity and cooperates with the divergence of the South Asian high-pressure anticyclonic circulation to form a large-scale environmental flow field favorable to the typhoon. Moreover, the typhoon biased the easterly wind in the north of the monsoon trough to the northerly wind until $110^{\circ} \mathrm{E}$, while the juvenile easterly wind only turned to $135^{\circ} \mathrm{E}$. Figure 10 shows the $700 \mathrm{hPa}$ wind field (a) from August to September 2016 and the $700 \mathrm{hPa}$ wind field (b) from August to September 1979-2016. It is obvious from the Figure 10 


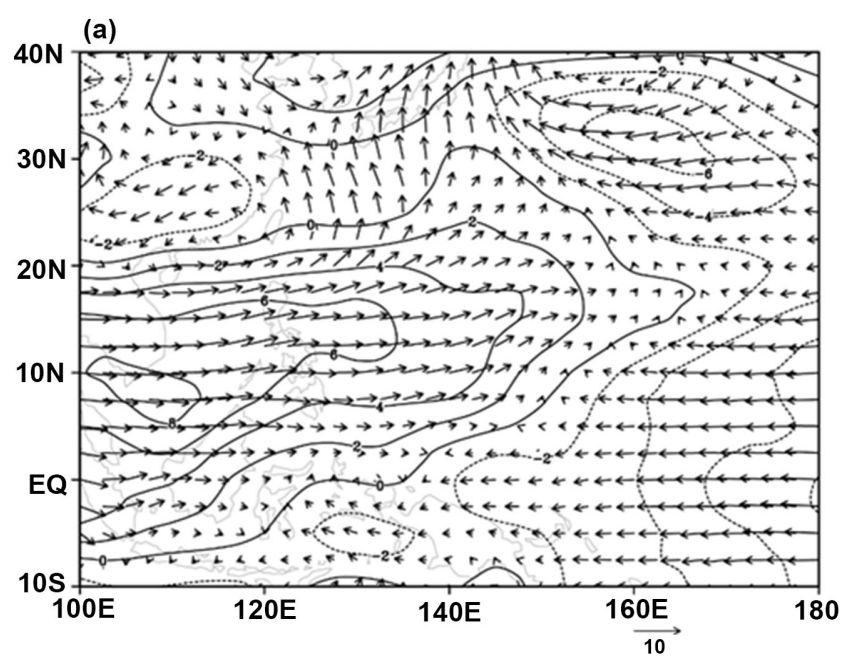

(b)

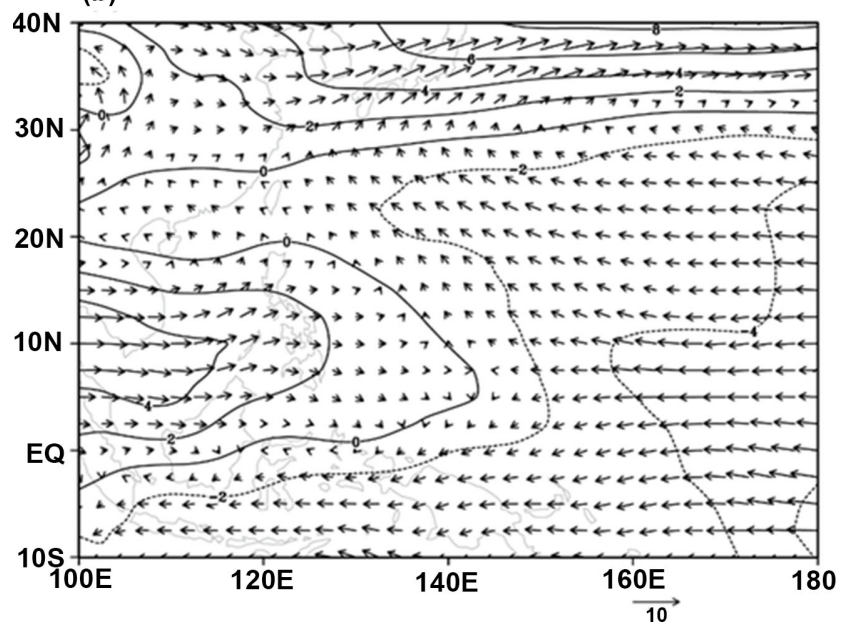

Figure 10. (a) Wind field in $700 \mathrm{hPa}$ from August to September in 2016, (b) climate average wind field in $700 \mathrm{hPa}$ (contour line for u-wind, unit: $\mathrm{m} / \mathrm{s}$ ).

that the position of the monsoon trough is significantly norther than normal. The eastern end of the monsoon trough has reached $175^{\circ} \mathrm{E}$, which is conducive to the formation of TC. In the August-September 2016, the tropical cyclone in the northeastern Pacific Ocean was more generated. At the same time, we also saw that the easterly wind in the north of the monsoon trough turned to the easterly wind at $120^{\circ} \mathrm{E}$, and the westerly wind near $10^{\circ} \mathrm{N}$ was $2 \mathrm{~m} / \mathrm{s}$ larger than normal. At the same time, the east wind is strong, which corresponds to the strong high intensity of the subtropical high intensity in August-September (Table 2). The situation has the favorable conditions for the initial disturbance generation. Therefore, the location and intensity of the monsoon trough also affects the TC generation in August-September 2016.

\subsection{Influence of Sea Temperature Field and Circulation Field}

Tropical cyclone activity is closely related to large-scale environmental fields, which the evolution of atmospheric circulation is in response to changes in SST 
in the tropics (Wang \&Chan, 2002; Lander, 1994). We explored the monthly evolution of the SST and air circulation in 2016 to explore the impact of the strong El Niño event in the following year on the formation and development of TCs. Huang et al. (2009) further studied the relationship between the frequency of typhoon in WNP and the sea surface temperature (SST). It is found that there is a significant hysteresis correlation coefficient between the sea temperature of the eastern equatorial Pacific and the frequency of TCs. The negative anomaly of SST will cause more TCs. More TCs will cause negative sea temperature anomalies in WNP. In the early 2016 (January-May), the monthly mean sea surface temperature in the eastern equatorial Pacific was abnormal, while in June the sea surface temperature in the eastern equatorial Pacific was significantly negative (figure omitted). The super El Niño event ended. Due to the lag effect of the SST anomaly, the western Pacific warm pool center caused the westward shift of the rising edge of the Walker circulation over the years, which in turn strengthened the convective activity of the tropical cyclone source in the western North Pacific and strengthened the lower atmosphere in the western Pacific. Convergence ( $\mathrm{Li}$, 1985) coincided with the results of the more tropical cyclone generation from August to September. The anomalous change of the sea temperature field leads to the change of the circulation field. Figure 11 is the $850 \mathrm{hPa}$ relative vorticity anomaly time-latitude profile. It is worth noting that the positive of $100^{\circ}-170^{\circ} \mathrm{E}$ The vorticity band (Figure 6) shows a trend from north to south. In September, the extreme center of the north vorticity band appeared in the north of $20^{\circ} \mathrm{N}$, which is $1.2 \times 10^{-5} \mathrm{~s}^{-1}$ larger than the average annual value. Strong intensity is conducive to the development of convective activities. However, the position of the negative vorticity extreme center (south of $5^{\circ} \mathrm{N}$ ) in the southern part of the South has not changed substantially. The negative vorticity zone of the South China Sea has evolved from south to north and turned into positive vorticity in

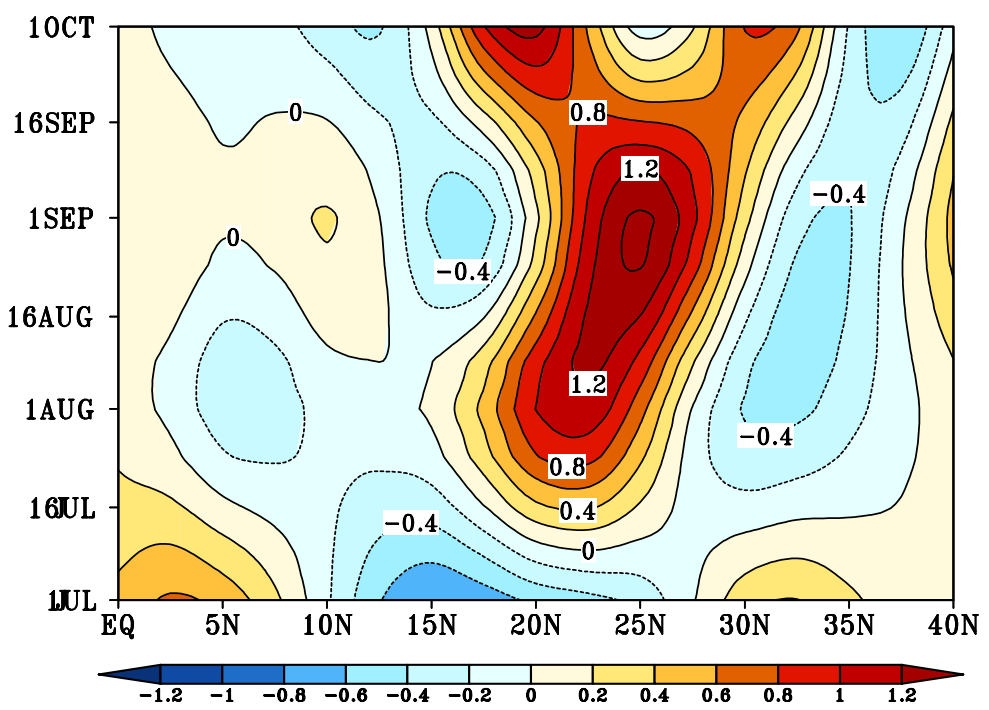

Figure 11. Time-latitude section of relative vorticity anomaly $\left(10^{5} \mathrm{~s}^{-1}\right)$ averaged in $100^{\circ}-170^{\circ} \mathrm{E}$ from August to September in 2016 . 
July, which explains why. From August to September 2016, the number of tropical cyclones in the northeastern part of the western Pacific and the South China Sea was more than that in the southeast, while the number of TCs in the southeast was less. This shows that the TC generation is closely related to the evolution of the low-level relative vorticity field, and the lag effect of the El Niño event on climate change has an important influence on the relative vorticity change.

\section{Conclusion}

Through statistical analysis, we study the characteristics of TC activity in the strong El Niño year over WNP and diagnose the environmental factors that caused the TC generation in August-September 2016. The conclusions are as follows.

In terms of the number of tropical cyclones generated and landed, strong El Niño has less TC generation in the first half of the year, and the typhoon active season in the second half of the year (July-September) has more TC generation and more typhoon landings. The number of typhoons in 2016 is in line with this law. It has a large number of generations, a late concentration of generation time, a concentrated source of production, a northerly position, and a steering path. The strong typhoon is concentrated in the autumn. The positive sea surface temperature anomalies and large-scale easterly anomalies in the western equatorial Pacific that the atmospheric stratification is unstable, which the initial disturbance of the lower layers is easy to develop in El Niño's decay during from August to September. The number of TC generations in 2016 was higher than previous years.

From August to September, the northerly position of the subtropical high caused ITCZ to be northerly, and the monsoon trough was also northerly. The south side of the subtropical high was a large area of southeast trade wind, and it was the area of vertical ascending motion, corresponding to the lower layer of $10^{\circ}-24^{\circ} \mathrm{N}$. A large area of positive vorticity anomalies between ${ }^{\circ} \mathrm{N}$, strong convergence and upward movement, active convection, is very conducive to the formation of tropical cyclones.

In August-September, the troposphere in the northeastern Pacific Ocean and the South China Sea has a small vertical wind shear, so that the latent heat released by condensation is always concentrated in a limited range, which is easy to form and develop the warm heart structure. One of the reasons for the large number of tropical cyclones in the northeastern Pacific and the South China Sea.

In addition, since TCs are products of sea-air mutual coupling that SST anomalies act as an important signal of climate change in WNP by through the subtropical high, the East Asian monsoon trough, and the Walker circulation bridge. Frequency of TC generation in WNP. From the perspective of extra-climate forcing factors, it is far from enough to rely on these factors to diagnose. 


\section{Conflicts of Interest}

The author declares no conflicts of interest regarding the publication of this paper.

\section{References}

Bai, L. N., He, M., Wang, Y. et al. (2010). The Influence of the Vertical Wind Shear Variation on Inter-Annual Changes in the Tropical Cyclone Activity in the Western North Pacific. Acta Meteorologica Sinica, 68, 877-884.

Chan J. C. L. (1985). Tropical Cyclone Activity in the Northwest Pacific in Relation to the El Niño/Southern Oscillation Phenomenon. Monthly Weather Review, 113, 599-606. https://doi.org/10.1175/1520-0493(1985)113<0599:TCAITN>2.0.CO;2

Chen, G. H., \& Huang, R. H. (2009). Dynamical Effects of Low Frequency Oscillation on Tropical Cyclogenesis over the Western North Pacific and the Physical Mechanisms. Chinese Journal of Atmospheric Sciences, 33, 205-214.

Chen, L. S., \& Ding, Y. H. (1979). Introduction to Typhoon in the Western North Pacific. Beijing: Science Press.

Ding, Y. H., \& Wright, E. R. (1984). Large-Scale Circulation Analysis Affecting the Frequency of Tropical Cyclones in the Western Pacific and North Atlantic. Acta Oceanologica Sinica, 6, 542-552.

Dong, K. (1988). El Niño and Tropical Cyclone Frequency in the Austrian Region and the Northwest Pacific. Australian Meteorological Magazine, 36, 219-225.

Emanuel, K. A. (2005). Increasing Destructiveness of Tropical Cyclones over the Past 30 Years. Nature, 436, 686-688. https://doi.org/10.1038/nature03906

Gao, J. Y., Zhang, X. Z. et al. (2008). Anomalous of Western North Pacific Monsoon Trough and Tropical Cyclones Activities. Acta Oceanologica Sinica, 30, 35-47.

He, M., Song, W. L. et al. (1999). Typhoon Activity in the Western North Pacific in Relation to El Niño/La Niña Events. Journal of Tropical Meteorology, 15, 18-26.

Hu, B. H. (2011). Research on Climatic Characteristics and Wind Field Calculation on Tropical Cyclones over Western North Pacific. Nanjing: Nanjing University.

Huang, Y., Li, C. Y. et al. (2009). Further Study on the Variation Characteristics of Tropical Cyclone Frequency and Its Relationship with Sea Surface Temperature in the Northwest Pacific. Journal of Tropical Meteorology, 25, 273-280.

Lai, F. F. (2011). The Inter-Annual Variation Characteristics of the Tropical Cyclone Intensity in the Western North Pacific and Mechanism Analysis. Nanjing: Nanjing University.

Lander, M. A. (1993). Comments on "AGCM Simulation of the Relationship between Tropical Storm Formation and ENSO". Monthly Weather Review, 121, 2137-2143. https://doi.org/10.1175/1520-0493(1993)121<2137:COGSOT>2.0.CO;2

Lander, M. A. (1994). An Exploratory Analysis of the Relationship between Tropical Storm Formation in the Western North Pacific and ENSO. Monthly Weather Review, 122, 636-651. https://doi.org/10.1175/1520-0493(1994)122<0636:AEAOTR>2.0.CO;2

Latif, M., Keenlyside, N., \& Bader, J. (2007). Tropical Sea Surface Temperature, Vertical Wind Shear, and Hurricane Development. Geophysical Research Letters, 34, L01710. https://doi.org/10.1029/2006GL027969

Li, C. Y. (1985). El Niño and Western North Pacific Typhoon Activities. Chinese Science Bulletin, 14, 1087-1089.

Li, C. Y. (1988). Actions of Typhoon over the Western Pacific (Including the South China 
Sea) and El Niño. Advances in Atmospheric Sciences, 5, 107-115. https://doi.org/10.1007/BF02657352

Liu, K. S., \& Chan, J. C. L. (2013). Inactive Period of Western North Pacific Tropical Cyclone Activity in 1998-2011. Journal of Climate, 26, 2614-2630. https://doi.org/10.1175/JCLI-D-12-00053.1

Maue, R. N. (2011). Recent Historically Low Global Tropical Cyclone Activity. Geophysical Research Letters, 38, L14803. https://doi.org/10.1029/2011GL047711

Ren, H. L., Liu, Y., Zuo, J. Q. et al. (2016). The New Generation of ENSO Prediction system in Beijing Climate Centre and Its Predictions for the 2014/2016 Super El Niño Event. Meteorology, 42, 521-531.

Shen, S. L., \& Jiang, J. (2010). Climate Background Analysis of Abnormal Year for Typhoons in Northwest Pacific. Meteorology, 36, 64-70.

Sun, L. (2010). Analysis of Features and Causation for Tropical Cyclone Activities over the Western North Pacific in 2010. Meteorological Monthly, 37, 929-935.

Vitart, F., Anderson, J. L., \& Stern, W. F. (1999). Impact of Large-Scale Circulation on Tropical Storm Frequency, Intensity, and Location, Simulated by an Ensemble of GCM Integrations. Journal of Climate, 12, 3237-3254. https://doi.org/10.1175/1520-0442(1999)012<3237:IOLSCO >2.0.CO;2

Wang, B., \& Chan, J. C. L. (2002). How Strong ENSO Events Affect Tropical Storm Activity over the Western North Pacific? Journal of Climate, 15, 1643-1658. https://doi.org/10.1175/1520-0442(2002)015<1643:HSEEAT>2.0.CO;2

Wang, H., Ding, Y. H. et al. (2006). Influence of Western North Pacific Summer Monsoon Changes on Typhoons Genesis. Acta Meteologica Sinica, 64, 345-346.

Wu, G., \& Lan, N. C. (1992). A GCM Simulation of the Relationship between Tropical Storm Formation and ENSO. Monthly Weather Review, 120, 958-977. https://doi.org/10.1175/1520-0493(1992)120<0958:AGSOTR>2.0.CO;2

Yao, X. P., Yu, Y. B. et al. (2006). Characteristics of Subtropical High during Abnormal Precipitation in the Huaihe River Basin in 2003. Journal of Tropical Meteorology, 4, 393-401.

Zhou, B. T., \& Cui, X. (2014). Interdecadal Change of the Linkage between the North Atlantic Oscillation and the Tropical Cyclone Frequency over the Western North Pacific. Science China Earth Sciences, 57, 2148-2155. https://doi.org/10.1007/s11430-014-4862-z

Zhu, Q. G., Lin, J. R. et al. (2007). Principles and Methods of Weather. Beijing: China Meteorological Press. 